\title{
Konsistensi Rencana Tata Ruang Permukiman Dan Arahan Kebijakan Pembangunan di Kabupaten Tanah Datar, Provinsi Sumatera Barat
}

\section{Spatial Plan Consistensy of Settlement and Development Policy Directions In Tanah Datar District, West Sumatra}

Iswandi Umar ${ }^{\mathrm{a}}$, Indang Dewata ${ }^{\mathrm{b}}$, Eri Barlian ${ }^{\mathrm{b}}$

a Jurusan Geografi, Fakultas Ilmu Sosial, Universitas Negeri Padang, Jln. Prof. Dr. Hamka Airtawar Padang, Padang, 25475, Indonesia

bPusat Penelitian Kependudukan dan Lingkungan Hidup (PPKLH) Universitas Negeri Padang, Jln. Prof. Dr. Hamka Airtawar Padang, Padang, 25475, Indonesia

${ }^{\mathrm{c}}$ Ketua Program Doktor Ilmu Lingkungan, Universitas Negeri Padang, Jln. Prof. Dr. Hamka Airtawar Padang, Padang, 25475, Indonesia

\section{Article Info:}

Received: 20 - 03 - 2018

Accepted: 05 - 07 - 2018

Keywords:

Policy direction, spatial plans, settlements.

Corresponding Author:

Iswandi Umar

Jurusan Geografi, Fakultas Ilmu

Sosial, Universitas Negeri

Padang, Padang;

Email: iswandi_u@yahoo.com

\begin{abstract}
In Indonesia the implementation of the spatial plan is only a small part of the plan. The impact of incompatibility with spatial planning is the deterioration of environmental quality. Tanah Datar District has a growth rate of settlements of 1.3 percent/year period 2000-2017. The purpose of this research is to determine index consistency of spatial plan and determination of policy direction of development of settlement area. To determine the consistency index of spatial planning to do a comparison between land use with the spatial plan. Land use map produced from Landsat ETM +8 , and map spatial plans resulting from the RTRW period 2008-2028 In Tanah Datar District. In addition, to determine the direction of the policy of settlement development using the ISM method. The number of elements analyzed by 10 elements, with 24 experts. The results show that around 43.7 percent of settlement development is incompatible with the spatial plan. Therefore, it is necessary for government policy to be consistent with spatial planning and law enforcement on spatial violations.
\end{abstract}

How to cite (CSE Style $8^{\text {th }}$ Edition):

Umar I, Dewata I, Barlian E. 2019. Konsistensi rencana tata ruang permukiman dan arahan kebijakan pembangunan di Kabupaten Tanah Datar, Provinsi Sumatera Barat. JPSL 9(2): 277-286. http://dx.doi.org/10.29244/jps1.9.2.277-286.

\section{PENDAHULUAN}

\section{Latar Belakang}

Proses pertumbuhan wilayah dipengaruhi oleh berbagai faktor baik yang bersifat internal maupun eksternal (Sirojuzilam 2007). Kaur et al. (2004) dan Sadyohutomo (2008) menyatakan bahwa faktor internal yang mendorong pertumbuhan wilayah adalah pertumbuhan penduduk, ekonomi, dan perdagangan. Selanjutnya Pribadi et al. (2006) dan Singalang dan Adji (2014) pertumbuhan wilayah yang pesat menyebabkan perubahan pola penggunaan lahan, dimana ruang terbangun semakin mendominasi dan mendesak ruang-ruang alami untuk berubah fungsi. Selain itu, Harun (1992) dan Kustiawan (1997) menjelaskan bahwa perubahan pola penggunaan lahan mengakibatkan terjadinya fluktuasi daya dukung sumberdaya lahan, sehingga menimbulkan terjadinya bencana alam.Penelitian Umar et al. (2017) di Kabupaten Tanah Datar terdapat sekitar 35.6 persen kawasan rawan bencana, dan sebesar 28.2 persen merupakan kawasan sangat rawan bencana longsor. 
UU No 26 Tahun 2007 tentang Penataan Ruang secara tegas menyatakan bahwa dalam penyusunan rencana tata ruang, terutama untuk kawasan permukiman, harus memperhatikan dan menghindari kawasan rawan bencana. Selanjutnya UNDP (1997) menyatakan bahwa terdapat dua permasalahan pokok dalam bidang permukiman yang dihadapi Indonesiia, yaitu peningkatan kebutuhan permukiman untuk pemenuhan kebutuhan penduduk dan pengelolaan permukiman yang telah terbangun. Rustiadi et al. (2011) menyatakan bahwa pentingnya penataan ruang dapat dibedakan atas tiga, yaitu:optimalisasi pemanfaatan sumberdaya, wujud distribusi sumberdaya, dan keberlanjutan.

KabupatenTanah Datar berdasarkan karakteristik fisik memiliki wilayah yang sangat rawan untuk terjadi bencana tanah longsor, antara lain: a) secara morfologi kawasan tersebut sekitar 55 persen merupakan kawasan relatif datar $(<27 \%)$; b) sekitar $70 \%$ kawasan Kabupaten Limapuluh Kota kawasan hutan primer beralih fungsi menjadi kawasan hutan sekunder; c) peningkatan intensitas curah hujan pada kawasan uppar DAS; dan d) semakin berkembangnya kawasan terbangun. BPBD Kabupaten Tanah Datar mencatat adanya terjadi peningkatan bencana tanah longsor baik dari frekuensi maupun luasan yang terkena dampak pada periode 2000-2017. Pada periode tersebut setiap tahunnya terjadi bencana tanah longsor sebanyak 3-5 kali, dan 20-30 persen terjadi pada kawasan permukiman.

\section{Tujuan Penelitian}

Berdasarkan latar belakang diatas tujuan penelitian ini untuk menentukan implementasi RTRW (20082028) untuk kawasan permukiman. Selain itu, penelitian ini juga merekondasikan arahan kebijakan pembangunan permukiman di Kabupaten Tanah Datar.

\section{METODE PENELITIAN}

\section{Lokasi dan Waktu Penelitian}

Penelitian ini dilaksanakan di Kabupaten Tanah Datar Provinsi Sumatera Barat. Secara geografis lokasi penelitian terletak pada bujur 100018'BT - 100050'BT dan lintang 0018'LS-0040'LS. Penelitian ini dilakukan dalam waktu enam bulan, dimulai bulan Juni - Desember 2017.

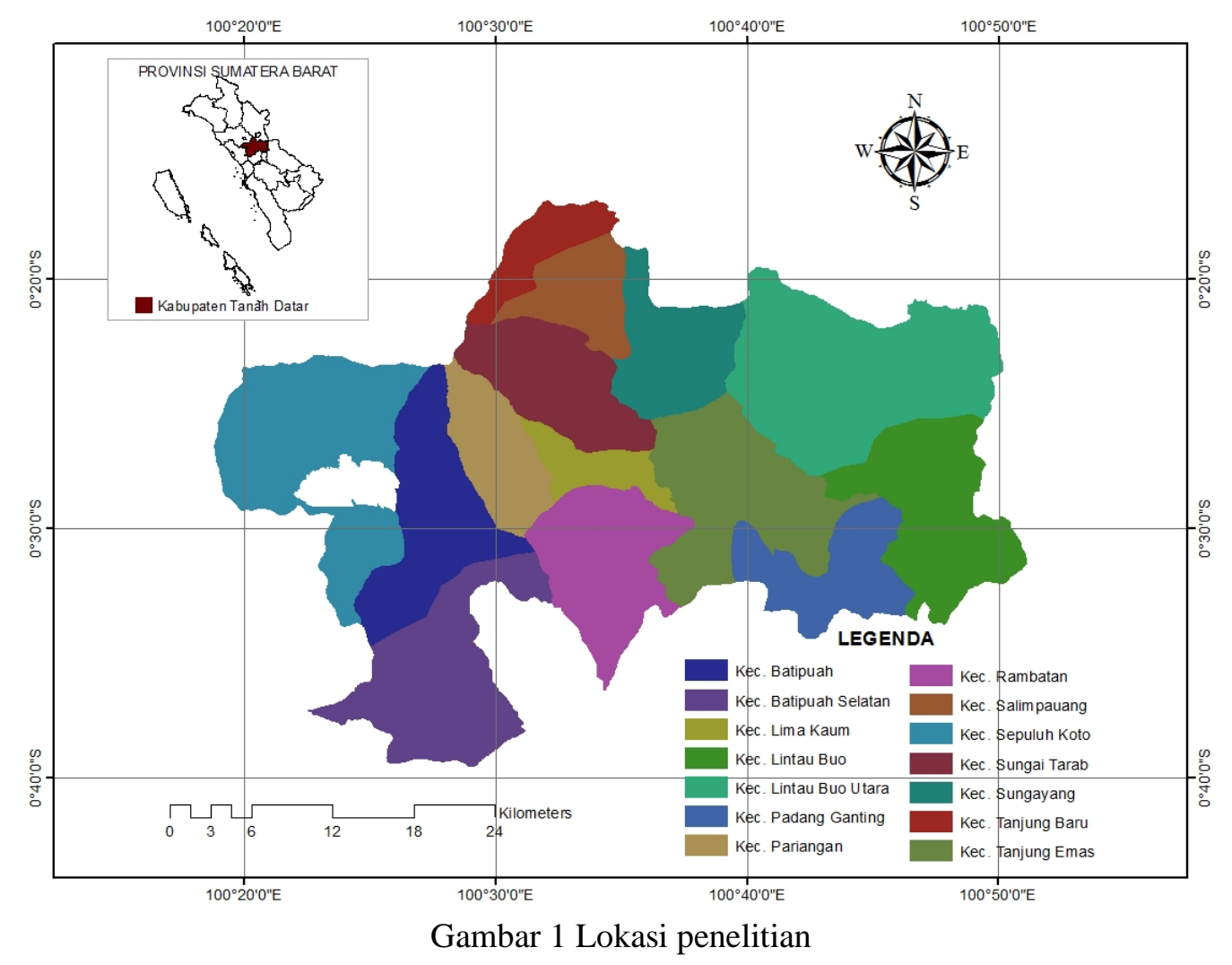




\section{Teknik Analisis Data}

Dalam menentukan indek inkonsistensi RTRW di Kabupaten Tanah Datar membutuhkan input dua peta tematik yakni peta penggunaan lahan dan peta pola ruang. Peta penggunaan lahan dihasilkan dari citra Landsat ETM+8, dan peta pola ruang dihasilkan RTRW Kabupaten Tanah Datar tahun 2008. Menurut Mutaáli (2013) inkonsistensi RTRW dapat dianalisis secara kuantitatif dengan menggunakan

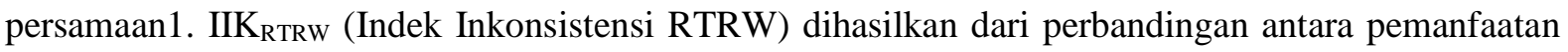
ruang (PRx) dengan rencana peruntukan kawasan (RPKy). Nilai indek yang dihasilkan antara 0-1, dimana semakin tinggi indek inkonsistensi maka semakin tinggi tingkat penyimpangan atau pelanggaran terhadap RTRW yang direncanakan.

$\mathrm{IIK}_{\mathrm{RTRW}}=\mathrm{PR}_{\mathrm{x}} / \mathrm{RPK}_{\mathrm{y}}$

Selain itu, indek konsistensi RTRW (IKRTRW) dihasilkan dari perbandingan antara rencana tata ruang untuk kawasan tertentu dengan pemanfaatan ruang yang sesuai dengan peruntukan kawasan tertentu. Indek konsistensi RTRW (IK $\mathrm{RTRW}_{\mathrm{W}}$ ) ditentukan dengan menggunakan persamaan 2.

IKRTRW= 1 - IIKRTRW

Arahan kebijakan pembangunan permukiman dianalisis menggunakan metode Interpretative Structural Modelling (ISM). Metode ISM dapat menganalisis dengan proses pengkajian kelompok melalui model struktural yang dihasilkan guna memotret perihal yang komplek dari suatu sistem melalui pola yang dirancang secara seksama dengan menggunakan grafis serta kalimat (Eriyatno dan Larasati 2013). Metode ISM cukup efektif untuk menstrukturkan isu-isu yang kompleks karena dapat digunakan untuk mendefinisikan dan memperjelas persoalan, menilai dampak dan mengidentifikasi hubungan antar kebijakan.

Prinsip dasar metode ISM adalah identifikasi dari struktur didalam suatu sistem yang memberikan nilai manfaat yang tinggi guna meramu sistem secara efektif dan untuk pengambilan keputusan yang lebih baik. Metodologi dari teknik ISM terdiri dari penyusunan hirarki dan klasifikasi sub elemen (Marimin 2004, Umar 2016, Umar et al. 2016, Santoso et al. 2017, Umar dan Dewata 2017). Secara garis besar tahapan metode ISM adalah sebagai berikut:

1) Penguraian setiap elemen menjadi beberapa sub elemen.

2) Penetapan hubungan konstekstual antar sub-elemen pada setiap elemen yang menunjukkan perbandingan berpasangan ada/tidak ada hubungan konstektual digunakan pendapat pakar.

3) Penyusunan Structural Self Interaction Matrix (SSIM) menggunakan simbol V, A, X dan O.

4) Pembuatan tabel Reachability Matrix (RM), mengganti simbol V, A, X dan O dengan bilangan 1 atau 0.

5) Melakukan perhitungan berdasarkan aturan transivity dimana matrik SSIM dikoreksi sampai terjadi matrik tertutup.

6) Melakukan level sub elemen pada setiap elemen menurut jenjang vertikal maupun horisontal.

7) Penyusunan matriks Driver Power Dependence (DPD) untuk setiap sub elemen. Klasifikasi elemen dibagi menjadi empat yaitu:

a. Kuadran I : Tidak berkaitan (Autonomous) terdiri dari sub elemen yang mempunyai nilai driver power $(\mathrm{DP}) \leq 0.5 \mathrm{X}$ dan nilai dependence $(\mathrm{D}) \leq 0.5 \mathrm{X}$. Dimana $\mathrm{X}$ adalah jumlah sub elemen pada setiap elemen. Sub elemen yang berada pada kuadran I umumnya tidak berkaitan/hubungannya kecil dengan sistem.

b. Kuadran II : Tidak bebas (Dependent) terdiri dari sub elemen yang mempunyai nilai driver power $(\mathrm{DP}) \leq 0.5 \mathrm{X}$ dan nilai dependence $(\mathrm{D}) \geq 0.5 \mathrm{X}$. Dimana $\mathrm{X}$ adalah jumlah sub elemen 
pada setiap elemen. Sub elemen yang berada pada kuadran II ini merupakan sub elemen yang tergantung pada elemen di kuadran III.

c. Kuadran III : Pengait (Linkage) terdiri dari sub elemen yang mempunyai nilai driver power (DP) $\geq 0.5 \mathrm{X}$ dan nilai dependence (D) $\geq 0.5 \mathrm{X}$. Dimana $\mathrm{X}$ adalah jumlah sub elemen pada setiap elemen. Sub elemen yang masuk pada kuadran III ini perlu dikaji secara hati-hati, karena setiap tindakan pada satu sub elemen akan berpengaruh pada sub elemen lain yang berada pada kuadran II dan IV.

d. Kuadran IV : Penggerak (Independent) terdiri dari sub elemen yang mempunyai nilai driver power $(\mathrm{DP}) \geq 0.5 \mathrm{X}$ dan nilai dependence $(\mathrm{D}) \leq 0.5 \mathrm{X}$. Dimana $\mathrm{X}$ adalah jumlah sub elemen pada setiap elemen.

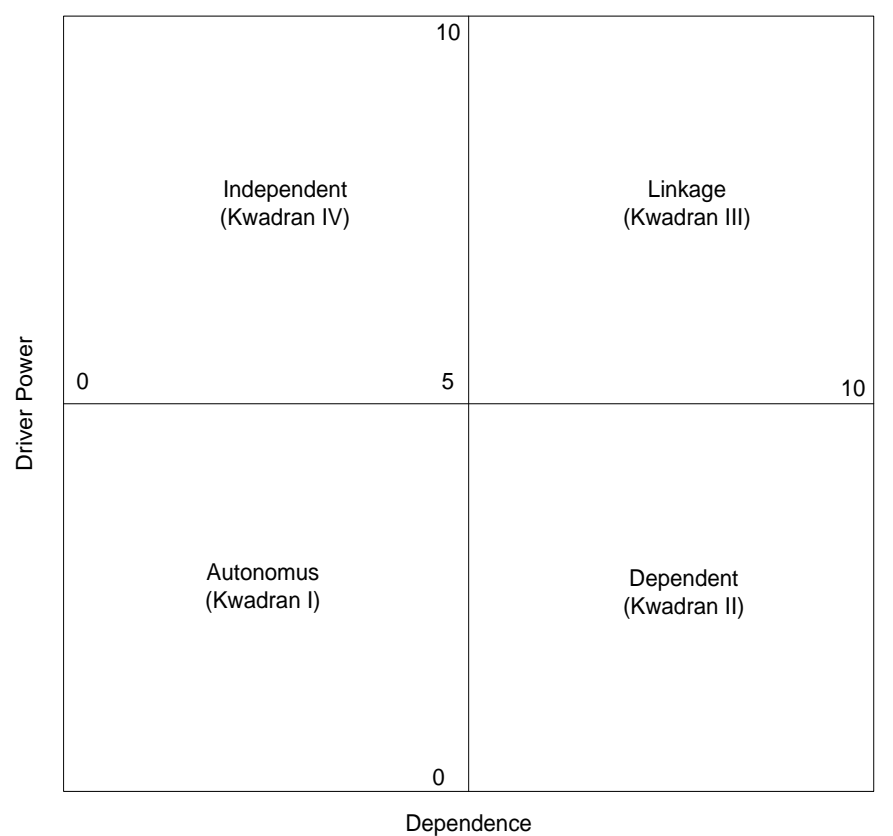

Gambar 2 Matrik hubungan driver power dengan dependence

Arahan kebijakan pengembangan kawasan permukiman disusun dengan melibatkan semua stakeholder yang terkait. Stakeholder yang terlibat dalam penelitian ini berjumlah sebanyak 28 orang yang berasal dari berbagai lembaga yang berhubungan dengan penyusunan rencana tata ruang wilayah. Melalui Forum Group Discation (FGD) diidentifikasi 10 sub elemen yang akan menjadi rencana arahan kebijakan, yaitu:

E1 : Rencana wilayah berbasis masyarakat

E2 : Pembuatan regulasi dan sanksi pelanggaran tata ruang

E3 : Paduserasi RTRW dan RDTR antar wilayah administrasi

E4 : Kerjasama dan singkronisasi antar lembaga terkait

E5 : Sosialisasi rencana tara ruang wilayah

E6 : Pengembangan SDM dalam rencana tata ruang

E7 : Konsistensi implementasi rencana tata ruang

E8 : Penegakan hukum dalam pelanggaran tata ruang

E9 : Pembuatan RTRW lebih detail

E10: Pembuatan standar teknis pemanfaatan ruang 
Dalam tahapan penelitian dapat dibedakan atas dua bagian, yaitu penentuan indek inkonsistensi tata ruang dan arahan kebijakan pembagunan permukiman. Gambar 3 disajikan tahapan-tahapan penelitian.

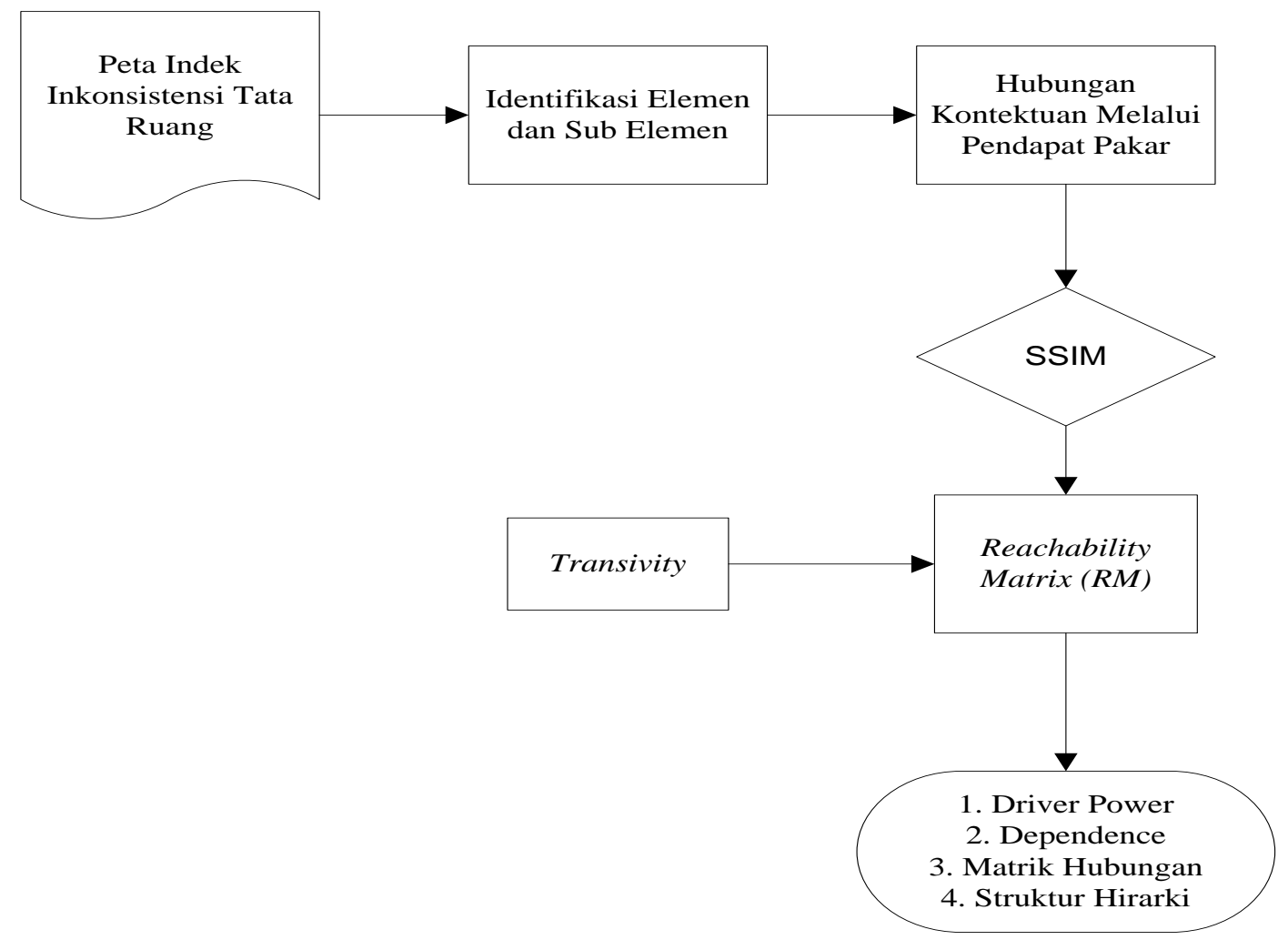

Gambar 3 Tahapan pelaksanaan penelitian

\section{Hasil dan Pembahasan}

Kabupaten Tanah Datar merupakan salah satu kabupaten di Provinsi Sumatera Barat dengan topografi yang bergelombang. Sekitar 65 persen wilayah tersebut memiliki kemiringan lereng lebih dari 27 persen. Kabupaten Tanah Datar berada pada lereng gunung Merapi, dan merupakan pusat kerajaan Minang Kabau yakni Pagaruyung. Selain itu, pertumbuhan penduduk pada periode 2000-2017 sebesar 1.2 persen pertahun. Pertumbuhan penduduk yang relatif tinggi mendorong peningkatan kebutuhan pemanfaatan lahan, baik untuk sektor pertanian maupun non pertanian.

Kawasan permukiman pada Kabupaten Tanah Datar selalu mengalami perkembangan setiap tahunnya. Persentase petumbuhan kawasan permukiman pada periode 2000-2016 sebesar 1.3 persen setiap tahunnya. Data BPS Tanah Datar (2016) persentase pertumbuhan penduduk pada wilayah penelitian sebesar 0.33 persen/tahun. Pertumbuhan kawasan permukiman berbanding lurus dengan peningkatan jumlah penduduk. Menurut Setiawan (2005) dan Umar et al. (2017) pemaanfaatan lahan tidak dapat dipisahkan dari kehidupan manusia Sedangkan lahan yang tersedia untuk dampat menampung kebutuhan manusia bersifat terbatas. Selain itu, Sadyohutomo (2008) menambahkan bahwa keterbatasan lahan yang dapat dimanfaatkan bagi kehidupan manusia menyebabkan terjadiknya konflik antar pengguna lahan. Selain itu, Muata'ali (2012) menyatakan bahwa pertambahan jumlah penduduk menyebabkan manusia memanfaatkan sumberdaya alam tanpa memperhatikan kemampuan dan daya dukung lingkungan. Sebagai akibatnya teerjadinya penurunan kualitas lingkungan dan bencana alam.

Kabupaten Tanah Datar terdapat 1354.8 Ha luas lahan permukiman, sedangkan lahan yang direncanakan untuk kawasan permukiman sebesar 4 984.4 Ha. Hasil analisis terdapat sebesar 2178.3 
Ha kawasan permukiman yang tidak sesuai dengan RTRW. Dengan menggunakan persamaan 1 dapat dihitung indek inkonsistensi RTRW sebesar 43.7. Sedangkan indek konsistensi RTRW pada Kabupaten Tanah Datar ditentukan dengan menggunakan persamaan 2 dengan nilai sebesar 56.3.

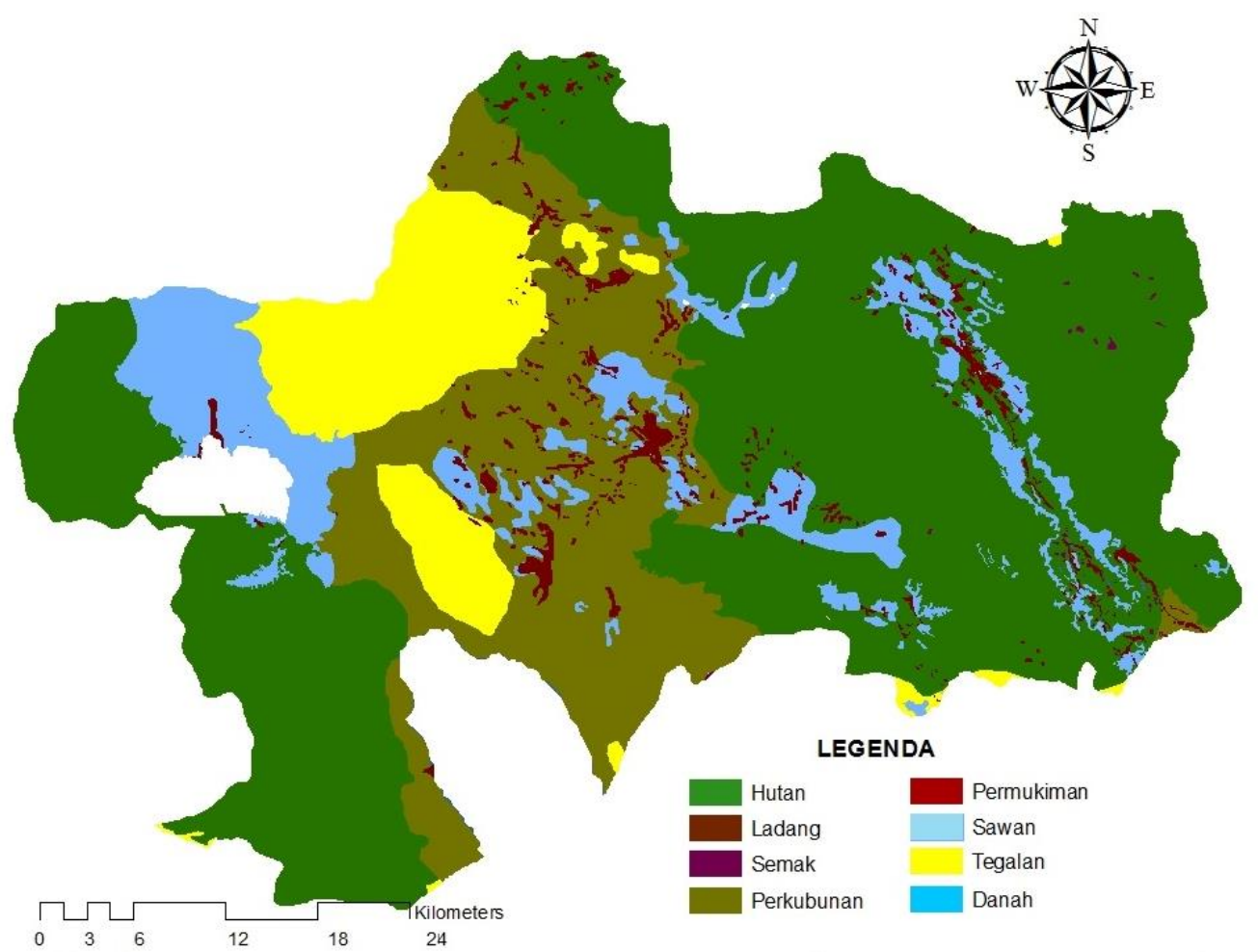

Gambar 4 Peta penggunaan lahan Kabupaten Tanah Datar hasil analisis tahun 2017

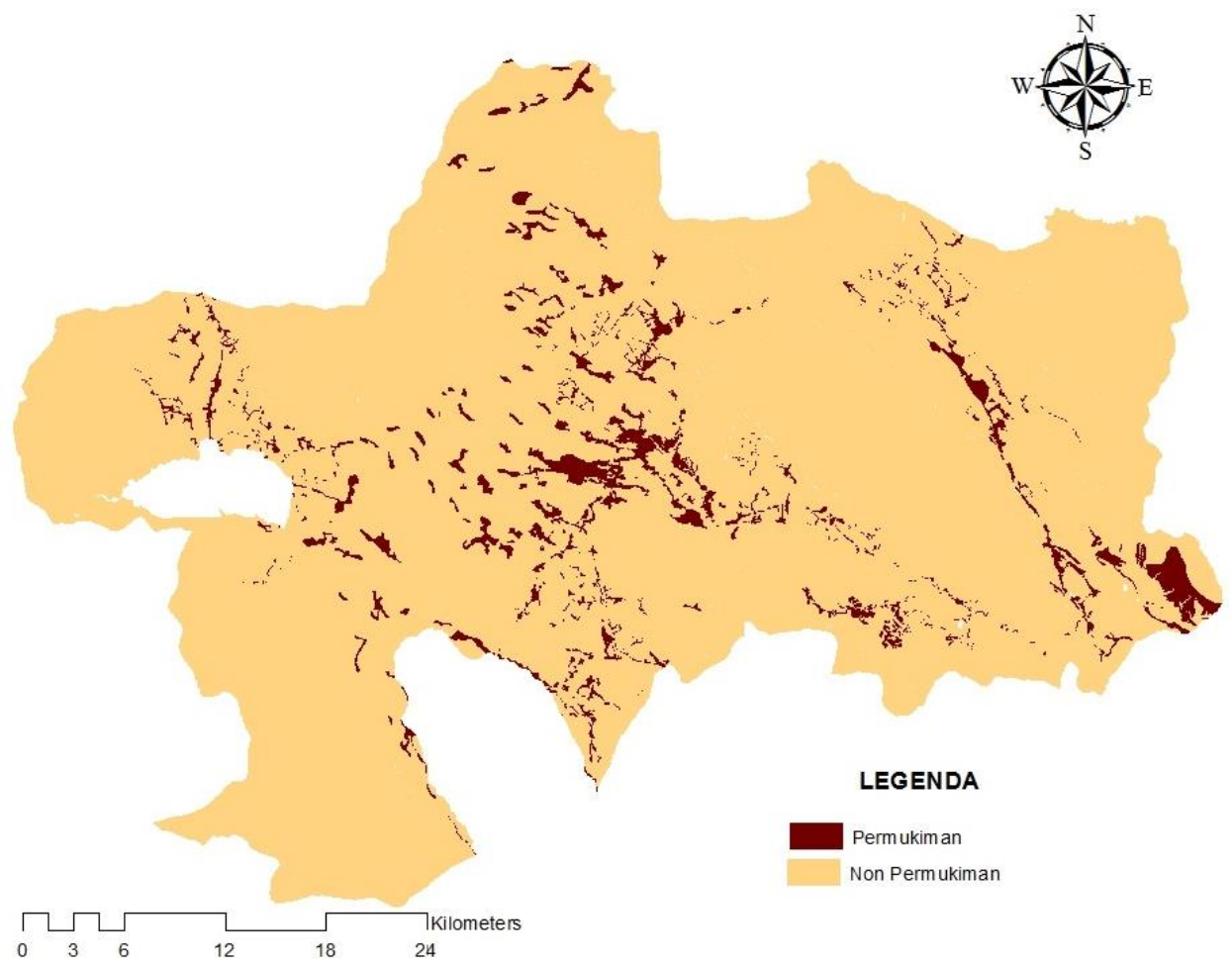

Gambar 5 Peta pola ruang permukiman (RTRW 2008-2024) di Kabupaten Tanah Datar hasil analisis tahun 2017 


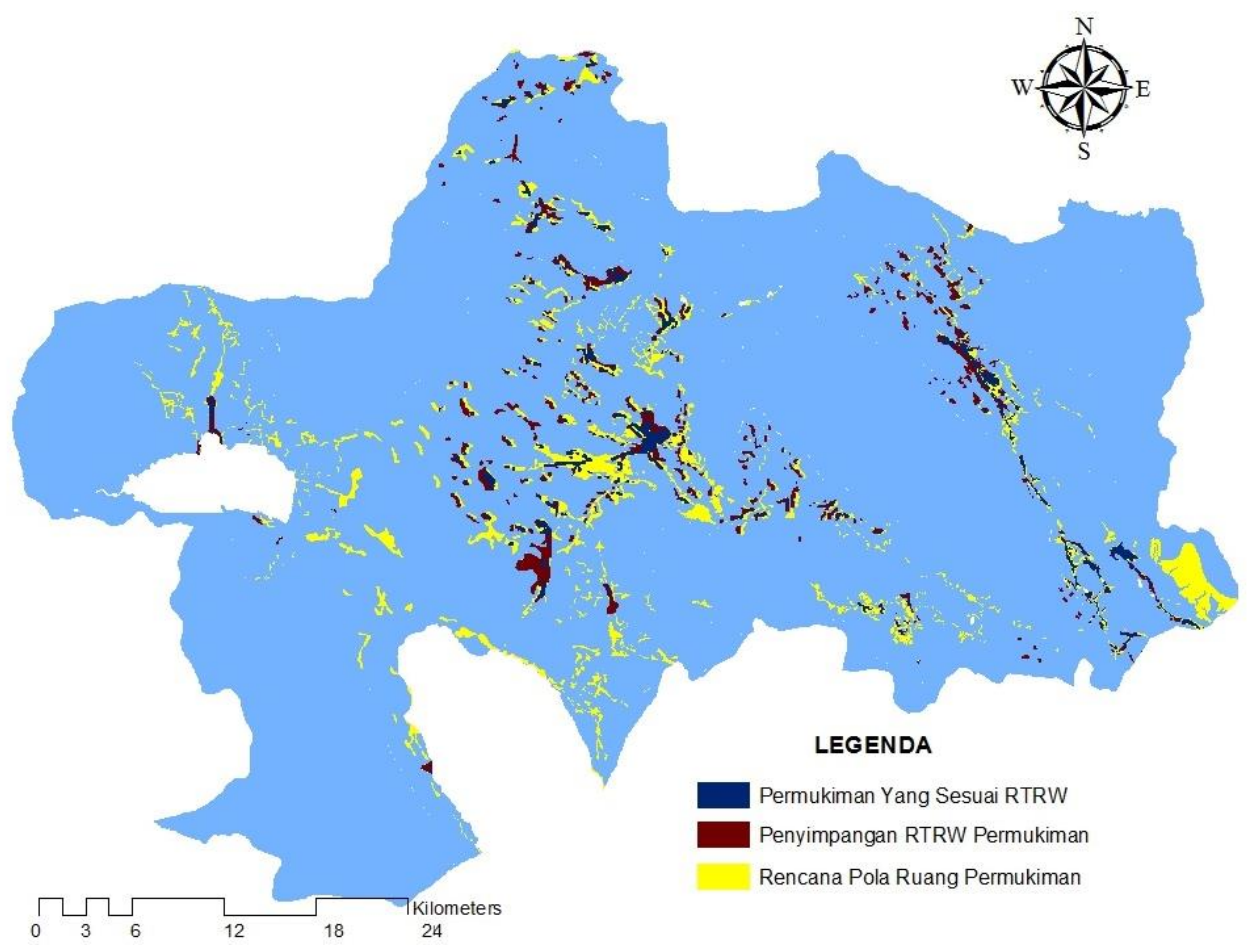

Gambar 6 Peta implementasi tata ruang permukiman di Kabupaten Tanah Datar hasil analisis tahun 2017

\section{Legenda}

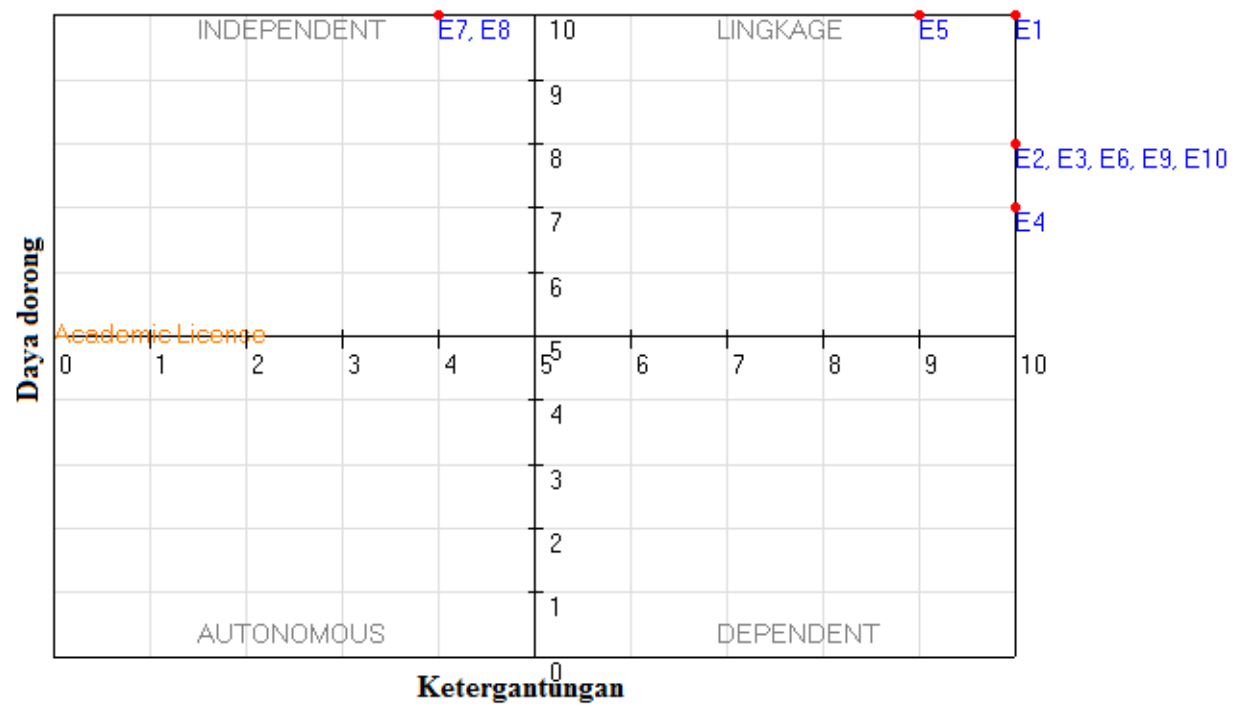

E1 : Rencana wilayah berbasis masyarakat

E2 : Pembuatan regulasi dan sanksi pelanggaran tata ruang

E3 : Paduserasi RTRW dan RDTR antar wilayah administrasi

E4 : Kerjasama dan singkronisasi antar lembaga terkait

E5 : Sosialisasi rencana tara ruang wilayah

E6 : Pengembangan SDM dalam rencana tata ruang

E7 : Konsistensi implementasi rencana tata ruang

E8 : Penegakan hukum dalam pelanggaran tata ruang

E9 : Pembuatan RTRW lebih detail

E10: Pembuatan standar teknis pemanfaatan ruang

Gambar 7 Diagram implementasi tata ruang untuk permukiman di Kabupaten Tanah Datar 


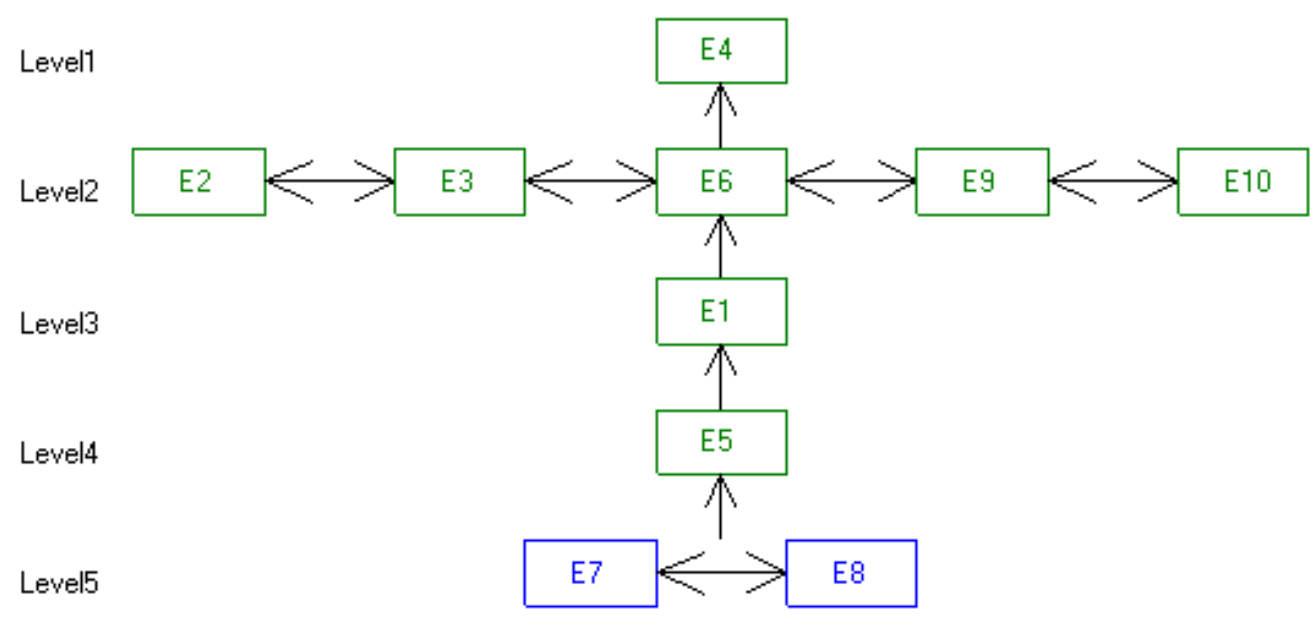

\author{
Legenda \\ E1 : Rencana wilayah berbasis masyarakat \\ E2 : Pembuatan regulasi dan sanksi pelanggaran tata ruang \\ E3 : Paduserasi RTRW dan RDTR antar wilayah administrasi \\ E4 : Kerjasama dan singkronisasi antar lembaga terkait \\ E5 : Sosialisasi rencana tara ruang wilayah \\ E6 : Pengembangan SDM dalam rencana tata ruang \\ E7 : Konsistensi implementasi rencana tata ruang \\ E8 : Penegakan hukum dalam pelanggaran tata ruang \\ E9 : Pembuatan RTRW lebih detail \\ E10: Pembuatan standar teknis pemanfaatan ruang
}

Gambar 8 Struktur implementasi tata ruang untuk permukiman di Kabupaten Tanah Datar

Gambar 4 merupakan peta penggunaan lahan pada tahun 2017 di Kabupaten Tanah Datar. Berdasarkan penggunaan lahan sebagian besar lahan dimanfaatkan sebagai kawasan hutan yakni sebesar 49.4 persen dari total luas wilayah, dan kawasan permukiman yakni sebesar 4.6 persen. Luas lahan yang direncanakan dalam tata ruang (RTRW) Kabupaten Tanah Datar sebesar 33.6 persen. Menurut Widyastomo (2011), Fauzia dan Prakoso (2012) dan Umar (2016) pemanfaatan ruang yang tidak sesuai dengan rencana tata ruang akan dapat mengakibatkan terganggunya rencana pemanfaatan ruang berkelanjutan. Selain itu, inkonsistensinya pemanfaatan ruang dapat menyebabkan degradasi lingkungan dan bencana alam. Mutaáli (2013) menyatakan indek inkonsistensi RTRW merupakan cerminan konflik antar penggunaan lahan.

Hasil analisis terhadap 10 sub elemen untuk arahan kebijakan tata ruang di Kabupaten Tanah Datar menunjukkan bahwa dua elemen termasuk pada kategori independen/ kuadran IV, dan delapan sub elemen berada pada kuandran lingkage/kuadran III. Hubungan daya dorong dan ketergantungan disajikan pada Gambar 7. Gambar 7 disajikan bahwa sub elemen E7 konsistensi implementasi rencana tata ruang dan sub elemen E8 penegakan hukum dalam pelanggaran tata ruang memiliki daya dorong yang tinggi (drive power). Selain itu, kedua sub elemen memiliki nilai ketergantungan yang rendah terhadap sub elemen yang lain.

Gambar 8 disajikan struktur implementasi RTRW Kabupaten Tanah Datar dalam analisis ISM terdapat lima tingkatan (level). Pada tingkatan yang paling tinggi (level 5) terdapat dua sub elemen yaitu sub elemen E7 konsistensi implementasi rencana tata ruang dan sub elemen E8 penegakan hukum dalam pelanggaran tata ruang. Sebagai sub elemen puncak maka kedua sub elemen tersebut menjadi kebijakan utama dalam arahan implementasi tata ruang di Kabupaten Tanah Datar. 


\section{SIMPULAN}

Kabupaten Tanah Datar memiliki lereng dan kawasan hutan lindung sebagai faktor pembatas (limiting factor) untuk pengembangan kawasan permukiman. Sekitar 70 persen kawasan tersebut merupakan kawasan dengan morfologi curam sampai terjal, sehingga perlu perencanaan matang dalam pemanfaatan pola ruang. Kabupaten Tanah Datar terdapat besar 43.7 persen pengembangan kawasan permukiman yang tidak sesuai (inkonsistensi) dengan RTRW. Untuk itu, arahan kebijakan pembangunan maka perlu dilakukan kemballi untuk konsistensi implementasi rencana tata ruang dan penegakan hukum untuk pelanggaran tata ruang.

Oleh karena itu, kepada pemerintahan Kabupaten Tanah Datar agar lebih konsistensi dalam pemberian izin pemanfaatan ruang. Selain itu, kepada Satuan Pamong Praja (Satpol PP) agar lebih tegas dalam menegakan dan penindakan terhadap pelanggaran tata ruang.

\section{DAFTAR PUSTAKA}

[BPS] Badan Pusat Statistik Kabupaten Tanah Datar. 2017. Tanah Datar Dalam Angka.

[BPBD] Badan Penanggulangan Bencana Daerah Kabupaten Tanah Datar. 2017. Data Statistik Bencana Alam Kabupaten Tanah Datar.

[Bappeda] Badan Perencanaan Pembangunan Daerah Kabupaten Tanah Datar. 2009. RTRW Kabupaten Tanah Datar Periode 2008-2028.

[UNDP] United Nations Development Programme. 1997. Agenda 21 Indonesia (Strategi Nasional untuk Pembangunan Berkelanjutan). Jakarta: Kantor Menteri Negara Lingkungan Hidup.

Darmawati, Saleh C, dan Hanafi I. 2015. Implementasi Kebijakan Rencana Tata Ruang Wilayah dalam Perspektif Pembangunan Berkelanjutan. Jurnal Ilmu Sosial dan Politik. 4(2), 378-384.

Eriyatno dan Larasati L. 2013. Ilmu Sistem Meningkatkan Integrasi dan Koordinasi Manajemen. Surabaya: Guna Widya Press.

Fauzia NA dan Pakoso BSE. 2012. Kajian Pengembangan Perumahan terhadap Ruang Wilayah Kabupaten Bekasi. Jurnal Perencanaan Wilayah dan Kota. 16(2), 182-192.

Harun UR. 1992. Dinamika Penggunaan Sumberdaya Lahan Di Jawa Barat. Jurnal PWK. 3, 48-53.

Kaur E, Palang H, dan Soovali H. 2004. Landscape in Change Opposing Attitudes in Saaremaa Estonia. Landscape and Urban Planing. 67(2), 109-120.

Kustiawan I. 1997. Permasalahan Konversi Lahan Pertanian dan Implikasinya terhadap Penataan Ruang Wilayah. Studi Kasus: Wilayah Pantura Jawa Barat. Jurnal PWK. 8, 49-60.

Marimin, 2004. Teknik dan Aplikasi Pengambilan Keputusan Kriteria Majemuk. Jakarta: Grasindo Press.

Mutaáli L. 2013. Penataan Ruang Wilayah dan Kota. Yogyakarta: Badan Penerbit Fakultas Geografi (BPFG) UGM.

Pribadi D, Shiddiq D, dan Ermyanila M. 2006. Model Perubahan Tutupan Lahan dan Faktor-faktor yang Mempengaruhinnya. Jurnal Teknologi Lingkungan BPPT. 3(1), 77-91.

Rustiadi E, Saefulhakim S, dan Panuju DR. 2011. Perencanaan dan Pengembangan Wilayah. Jakarta: Cerpen Press.

Santoso P B, Widiatmaka, Sabiham S, dan Rusastra IW. 2017. Analisis Pola Konservasi Lahan Sawah dan Struktur Hubungan Penyebab dan Pencegahannya (Studi Kasus Kabupaten Subang, Provinsi Jawa Barat). Jurnal Pengelolaan Sumberdaya Alam dan Lingkungan. 7(2), 184-194.

Sadyohutomo M. 2008. Manajemen Kota dan Wilayah Realitas dan Tantangan. Jakarta: Penerbit Bumi Akasara 
Setiawan A. 2005. Fenomena Kawasan Permukiman yang Indivualis. Jurnal Smartek. 3(2), 113-124.

Sirojuzilam. 2007. Spatial Planning and Regional Planning. Jurnal Perencanaan dan Pengembangan Wilayah. 2(3): 142-149.

Singalang I dan Adji F. 2014. Pengaruh Kondisi Hunian dan Lingkungan Terhadap Keberlanjutan Permukiman Tepi Sungai Studi Kasus Kampung Pahandut dan Desa Danau Tundai Di Kota Palangka Raya. Jurnal Perspektif Arsitektur. 9(2): 47-58.

Syahadat E, dan Sabarudin. 2012. Problems on Forest and Land Use System for Revision of Provincial Land Use System. Jurnal Analisis Kebijakan Kehutanan. 9(2), 131-143.

Umar I. 2016. Mitigasi Bencana Banjir pada Kawasan Permukiman Di Kota Padang, Provinsi Sumatera Barat. Disertasi. Bogor: Sekolah Pascasarjana IPB.

Umar I, Widiatmaka, Pramudya B, dan Barus B. 2016. Institutional Hierarchy of Flood Mitigation for Settlement Areas in Padang, West Sumatera. Public Policy and Administration Research. 6(7), 2734.

Umar I dan Dewata I. 2017. Pendekatan Sistem. Jakarta: Rajawali Press.

Umar I, Dewata I, Barlian E, dan Hermon D. 2017. Zona Rawan Longsor pada Kawasan Permukiman Di Kabupaten Tanah Datar. Pengelolaan Daerah Aliran Sungai Secara Terpadu (pp. 39-45). Pakanbaru: Lembaga Penelitian dan Pengabdian Kepada Masyarakat UNDRI.

Umar I, Widiatmaka, Pramudya B, dan Barus B. 2016. Institutional Hierarchy of Flood Mitigation for Settlement Areas in Padang, West Sumatera. Public Policy and Administratin Research. 6(7), 2734.

Widyastomo D. 2011. Perubahan Pola Permukiman Tradisional Suku Sentani di Pesisir Danau Sentani. Jurnal Permukiman. 6(2), 84-92. 